PREPARED FOR THE U.S. DEPARTMENT OF ENERGY, UNDER CONTRACT DE-AC02-76CH03073

PPPL-3551

PPPL-3551

UC-70

\title{
Surface Treatment of a Lithium Limiter for Spherical Torus Plasma Experiments
}

R. Kaita, R. Majeski, R. Doerner, G. Antar, J. Timberlake, J. Spaleta, D. Hoffman, B. Jones, T. Munsat, H. Kugel, G. Taylor, D. Stutman, V. Soukhanovskii, R. Maingi, S. Molesa, P. Efthimion, J. Menard, M. Finkenthal, and S. Luckhardt

March 2001
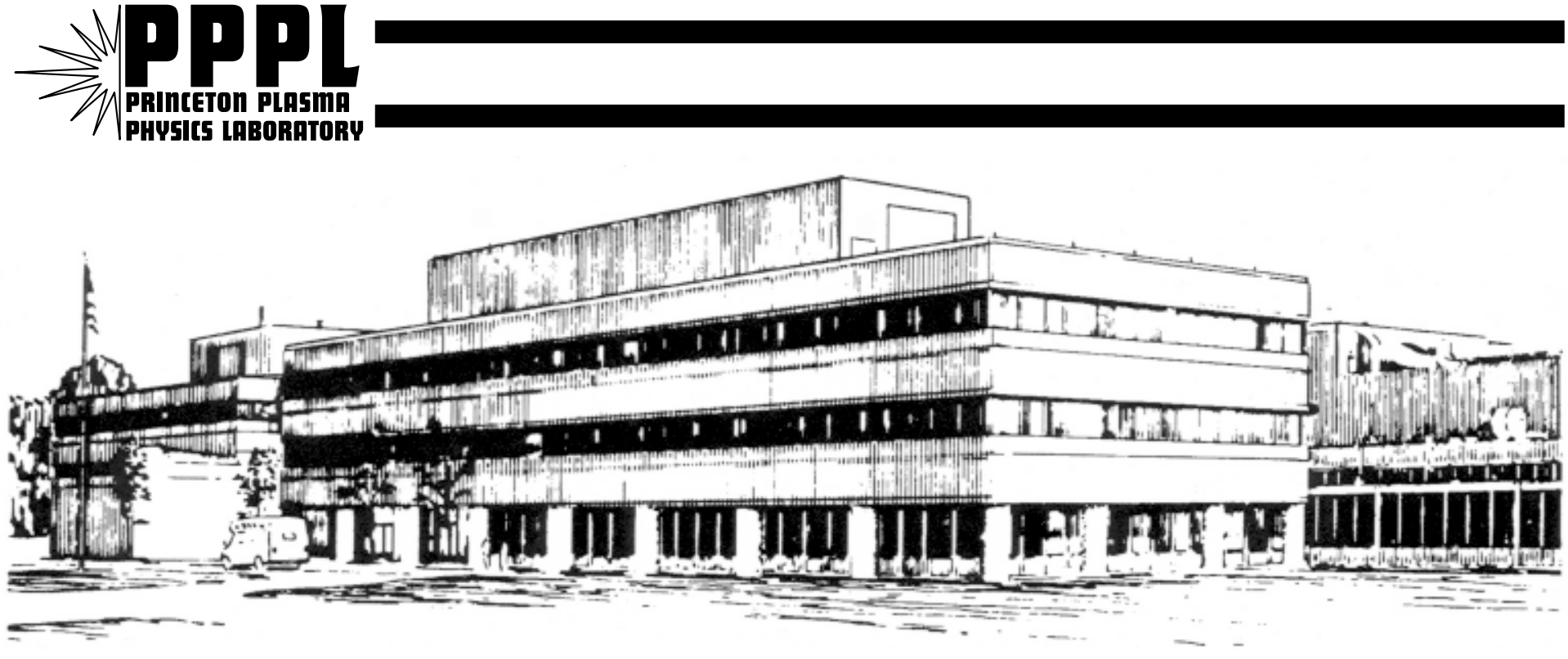

PRINCETON PLASMA PHYSICS LABORATORY PRINCETON UNIVERSITY, PRINCETON, NEW JERSEY 


\section{PPPL Reports Disclaimer}

This report was prepared as an account of work sponsored by an agency of the United States Government. Neither the United States Government nor any agency thereof, nor any of their employees, makes any warranty, express or implied, or assumes any legal liability or responsibility for the accuracy, completeness, or usefulness of any information, apparatus, product, or process disclosed, or represents that its use would not infringe privately owned rights. Reference herein to any specific commercial product, process, or service by trade name, trademark, manufacturer, or otherwise, does not necessarily constitute or imply its endorsement, recommendation, or favoring by the United States Government or any agency thereof. The views and opinions of authors expressed herein do not necessarily state or reflect those of the United States Government or any agency thereof.

\section{Availability}

This report is posted on the U.S. Department of Energy's Princeton Plasma Physics Laboratory Publications and Reports web site in Calendar Year 2001. The home page for PPPL Reports and Publications is: http://www.pppl.gov/pub_report/

DOE and DOE Contractors can obtain copies of this report from:

U.S. Department of Energy

Office of Scientific and Technical Information

DOE Technical Information Services (DTIS)

P.O. Box 62

Oak Ridge, TN 37831

Telephone: (865) 576-8401

Fax: (865) 576-5728

Email: reports@adonis.osti.gov

This report is available to the general public from:

National Technical Information Service

U.S. Department of Commerce

5285 Port Royal Road

Springfield, VA 22161

Telephone: 1-800-553-6847 or

(703) 605-6000

Fax: (703) 321-8547

Internet: http://www.ntis.gov/ordering.htm 


\title{
Surface Treatment of a Lithium Limiter for Spherical Torus Plasma Experiments
}

\author{
R. Kaita 1), R. Majeski 1), R. Doerner 2), G. Antar 2), J. Timberlake 1), J. Spaleta 1), \\ D. Hoffman 1), B. Jones 1), T. Munsat 1), H. Kugel 1), G. Taylor 1), D. Stutman 3), \\ V. Soukhanovskii 1), R. Maingi 4), S. Molesa 5), P. Efthimion 1), \\ J. Menard 1), M. Finkenthal 3), S. Luckhardt 2)
}

1) Princeton Plasma Physics Laboratory, Princeton, NJ, USA

2) University Of California at San Diego, La Jolla, CA, USA

3) Johns Hopkins University, Baltimore, MD, USA

4) Oak Ridge National Laboratory, Oak Ridge, TN, USA

5) Hope College, Holland, MI, USA

\begin{abstract}
The concept of a flowing lithium first wall for a fusion reactor may lead to a significant advance in reactor design, since it could virtually eliminate the concerns with power density and erosion, tritium retention, and cooling associated with solid walls. As part of investigations to determine the feasibility of this approach, plasma interaction questions in a toroidal plasma geometry are being addressed in the Current Drive eXperiment - Upgrade (CDX-U) spherical torus (ST). The first experiments involved a toroidally-local lithium limiter (L3). Measurements of pumpout rates indicated that deuterium pumping was greater for the L3 compared to conventional boron carbide limiters. The difference in the pumpout rates between the two limiter types decreased with plasma exposure, but argon glow discharge cleaning was able to restore the pumping effectiveness of the L3. At no point, however, was the extremely low recycling regime reported in previous lithium experiments achieved. This may be due to the much larger lithium surfaces that were exposed to
\end{abstract}


the plasma in the earlier work. The possibility will be studied in the next set of CDX-U experiments, which are to be conducted with a large area, fully toroidal lithium limiter. 


\section{INTRODUCTION}

Reactor studies[1] have identified liquid walls as a potentially "revolutionary" solution of generic magnetic fusion energy (MFE) first-wall problems, such as heat load and erosion limits of dry walls, neutron damage and activation, reliability/maintainability of first walls, and tritium inventory and breeding. To address the practicality of this concept, key liquid lithium-plasma interaction questions are being addressed in the CDX-U device[2] at the Princeton Plasma Physics Laboratory (PPPL). Initial investigations were performed with a liquid lithium limiter (L3) probe supplied by the University of California at San Diego (UCSD). These experiments will be followed by discharges utilizing a large area liquid lithium pool as the target.

The benefits of a surface that has low or no recycling conditions have been demonstrated during the "Deposition of Lithium by Laser Outside of Plasma" (DOLLOP) lithium wall conditioning experiments,[3] for example, in the Tokamak Fusion Test Reactor (TFTR). Lithium limiter experiments have also been performed on the T-11M device,[4] where a Capillary Porous System (CPS) was used to form a "self-restoring" liquid lithium limiter surface.[5] However, introduction of large area lithium limiter targets and walls into existing tokamak facilities has not yet taken place. The primary goal of CDX-U will thus be to study auxiliary-heated discharge whose surface contact is primarily with a large-area liquid lithium limiters.

Surface conditioning was identified as a critical issue in both the TFTR and T-11M experiments. The DOLLOP process was a technique where the graphite plasma facing components in TFTR were conditioned with the deposition of a lithium surface film. Particle recycling in T-11M was reportedly reduced only after plasma operations were conducted long enough to clean the CPS limiter surface. For this reason, considerable effort was dedicated to the conditioning of the L3 probe head on CDX-U. 
This paper provides a brief description of CDX-U and L3 (Section II). This is followed by the procedure to prepare the L3 for plasma exposure in Section III. Three discharge conditions are then described in Section IV. The first case (Case A) involved a solid L3 head that was loaded with lithium several days before plasma exposure, but was kept under vacuum prior to its use. In the second case (Case B), the L3 head was exposed to deuterium plasmas for about a day. It was subsequently left for several days under vacuum and was not discharged cleaned. For the final case (Case C), the L3 head was discharge cleaned for a half hour with argon, and exposed to deuterium plasmas while kept above the melting point of lithium.

The results of the argon glow discharge cleaning are described in Section IV. Pumpout rate measurements indicated that initially, the deuterium pumping was greater for the L3 compared to conventional boron carbide limiters. The difference between the two limiters decreased with plasma exposure, as the recycling became higher, the oxygen emission increased, and the appearance of the L3 surface changed from shiny to dull. Argon glow discharge cleaning was able to restore the surface appearance and pumping effectiveness of the L3.

The conclusions are summarized in Section V. The low recycling regime reported in previous lithium experiments was never achieved in the L3 experiments to date, perhaps due to the much larger lithium surfaces that were exposed to the plasma in the earlier work. To investigate this possibility, a fully toroidal lithium limiter is being installed in CDX-U. The surface area is about $2300 \mathrm{~cm}^{2}$, which will provide a larger area for the interaction between the CDX-U plasma and the lithium surface.

\section{DESCRIPTION OF CDX-U AND THE L3 PROBE}

The CDX-U facility (Fig. 1) is capable of spherical plasma operations in toroidal fields up to 2.3 kG with a "flattop" of $100 \mathrm{~ms}$. Power supplies for the vertical and shaping fields permit 
discharges with plasma current up to $150 \mathrm{kA}$ for greater than $25 \mathrm{~ms}$. At present, the Ohmic heating capacitor banks limit the plasma current to about $80 \mathrm{kA}$. All of the power supplies (with the exception of the capacitor banks for the Ohmic heating system and the field null formation coils) are preprogrammed and controlled by digital to analog waveform generators. The basic discharge parameters summarized in Table 1 and Fig. 2.

\begin{tabular}{|c|c|}
\hline Major Radius $\left(\mathrm{R}_{0}\right)$ & $34 \mathrm{~cm}$ \\
\hline Minor Radius $(\mathrm{a})$ & $22 \mathrm{~cm}$ \\
\hline Aspect Ratio $\left(\mathrm{R}_{0} / \mathrm{a}\right)$ & $\geq 1.5$ \\
\hline Elongation $(\kappa)$ & $\leq 1.6$ \\
\hline Triangularity $(\delta)$ & $>0.2$ \\
\hline Toroidal Field $\left(\mathrm{B}_{\mathrm{t}}\right)$ & $0.23 \mathrm{Tesla}$ \\
\hline $\begin{array}{c}\text { Ohmic Current }\left(\mathrm{I}_{\mathrm{p}}\right) \\
\text { Pauxiliary (radio }\end{array}$ & $\leq 80 \mathrm{kA}$ \\
\hline \begin{tabular}{l} 
frequency heating $)$ \\
\hline
\end{tabular}
\end{tabular}

Table 1. CDX-U parameters.

The Ohmic heating system is capable of providing 0.2 MW to CDX-U, and the facility also has a radio frequency $(\mathrm{RF})$ heating system[2] that is rated at $0.3 \mathrm{MW}$. The resulting parallel and normal heat fluxes will be $8-10 \mathrm{MW} / \mathrm{m}^{2}$ and 2-3 $\mathrm{MW} / \mathrm{m}^{2}$, respectively, over 25 to $50 \mathrm{~ms}$ because of the compact ST geometry.

The L3 probe was developed at UCSD for the first experiments involving the use of solid and liquid lithium as a plasma limiter in CDX-U. The head of the L3 probe is a lithium covered rail 5 $\mathrm{cm}$ in diameter and $20 \mathrm{~cm}$ long (Fig. 3). The rail can be inserted or removed via a double gate valve airlock system to prevent exposure of the lithium to air. When the limiter is fully inserted, it 
forms the upper limiting surface for the discharge and is intended to define the last closed flux surface for the discharge (Fig. 1). If the limiter is retracted, ceramic boron carbide rods form the upper limiting surface for the discharge. The limiter has an internal heater and has been operated in contact with the plasma over the temperature range of $20-300^{\circ} \mathrm{C}$.

\section{PREPARATION OF THE L3 FOR USE WITH PLASMAS}

The initial loading of the L3 head with lithium was conducted in a glove box separate from CDXU. The glove box enclosed the end of L3 probe assembly, which included a special loading chamber for the L3 head. The glove box was kept filled with argon.

A reservoir was attached to the top of the loading chamber. The reservoir was filled with solid lithium that was stored in bags containing argon and sealed by the supplier. The reservoir temperature was raised to $500^{\circ} \mathrm{C}$ using an internal electric heater. The liquid lithium was allowed to drip from an opening in the base of the reservoir onto the L3 head. The head is covered with a stainless steel mesh, which absorbed the lithium as the head was moved slowly beneath the reservoir.

Once the lithium cooled, the L3 head was retracted from the loading chamber and sealed with a gate valve. The L3 probe assembly also has a replenishing reservoir, which can be filled through an opening on the end opposite the probe head. This end was placed in the glove box after the head was loaded with lithium, and filled with solid lithium in an argon atmosphere.

The L3 probe assembly was evacuated and attached to CDX-U through an "airlock" (two valves shown in Fig. 1) prevent exposure of the L3 head to air. It was maintained at a pressure of about 2 $\mathrm{x} 10^{-7}$ torr for approximately two weeks. The L3 head was thus either in an argon atmosphere or under vacuum before it was exposed to CDX-U discharges. Visual inspection of the head 
immediately before plasma exposure indicated that it was as shiny as it was immediately after it was coated with lithium (Fig. 3).

\section{INITIAL PLASMA OPERATIONS AND GLOW DISCHARGE CLEANING}

The results of the first operation of CDX-U with a solid lithium limiter (Case A) are shown in Fig. 4. The lower curve is the $\mathrm{D}_{\alpha}$ emission at the $\mathrm{L} 3$ head after its exposure to only a few CDX-U plasmas. The upper curve corresponds to the emission from Case B. The L3 head was exposed to about a dozen discharges, kept at a pressure of about $2 \times 10^{-7}$ torr for several days, and exposed to the plasma once again when the $\mathrm{D}_{\alpha}$ emission was measured. The deuterium prefill required to obtain breakdown was $\approx 60 \%$ higher in Case A relative to Case $\mathrm{B}$, which also suggests a difference in surface cleanliness.

The appearance of L3 head was markedly different before (Case A) and after plasma exposure (Case B). The surface changed from being shiny and metallic to a mottled combination of dull gray and brown. The first attempt at cleaning the surface was simply to raise the temperature well above the melting point of lithium. Even at $400^{\circ} \mathrm{C}$, or over twice the melting point of lithium, the surface did not appear to liquefy, and there was no change in the surface appearance. This suggests that the surface content responsible for the mottled appearance was not volatilized or decompose significantly at temperatures up to this level. The result is consistent with earlier work, which showed that temperatures between $800^{\circ} \mathrm{C}$ and $1200^{\circ} \mathrm{C}$ may be needed, depending on the nature of the coating.

The GDC with argon as the working gas was more successful in restoring the surface of the L3 head to its original shiny and metallic appearance. The L3 head served as the cathode. With a bias voltage of about 250 volts, the arc drew a current of about 0.25 amperes at a pressure of about 70 
millitorr. Under these argon ion bombardment conditions, the head achieved a temperature of about $250^{\circ} \mathrm{C}$ and the lithium liquefied.

Figure 5 shows measurements with a residual gas analyzer during glow discharge cleaning. The primary constituents are hydrogen, water, carbon monoxide, and carbon dioxide. As the temperature rises and the lithium surface is cleaned, there is a noticeable rise in the hydrogen level. One explanation is that the water released from the plasma facing components (PFC's) during plasma operations reacts with the lithium on the L3 head. This produces lithium hydroxide, which dissociates during GDC to produce the observed hydrogen.

If lithium deuteride were formed, its dissociation during GDC would lead to the formation of molecular deuterium and the molecular combination of hydrogen and deuterium. Neither species is conspicuous in the RGA spectrum, which suggests that deuteride formation was minimal. This observation thus argues against the creation of a lithium deuteride coating that stops the deuterium absorption and changes the recycling at the limiter surface.

The low levels of deuterium are also consistent with the small amount of gas that was needed for plasma operations. The deuterium prefill for CDX-U discharges was typically $\approx 10^{-4} \mathrm{~T}$, which corresponds to $5 \times 10^{18}$ molecules. Even if all of this gas reacted with the lithium, the amount of lithium deuteride formed during each discharge would have been about 70 micrograms. This agrees with observations on $\mathrm{T}-11 \mathrm{M}$, where desorption of deuterium is reported, but not the formation of lithium deuteride.[6]

Figure 6 is a photograph of the L3 head during GDC, which still shows the mottling in its central region. The entire surface of the head was no longer dull and mottled, but became comparable in brightness prior to plasma exposure. When the L3 head was originally coated, there were parts of the mesh that did not contain lithium. As the GDC progressed, these areas became covered when 
the lithium liquefied and flowed around the head. The GDC was typically continued for about a half hour after the $\mathrm{L} 3$ head temperature reached $250^{\circ} \mathrm{C}$. This time was well after the effluent levels were at a minimum.

The replenishing reservoir mentioned in Section III was designed to permit the addition of lithium to the L3 head without removing the probe assembly from CDX-U. If there was no lithium present on the stainless steel mesh that surrounded the L3 head, the liquid lithium had to be dripped from above as the head was moved beneath it. If the stainless steel mesh already contained liquid lithium, however, it was supposed to absorb the lithium as it was forced out of the fixed replenishing reservoir tube. The flow properties of liquid lithium were demonstrated dramatically during one GDC attempt.

Argon GDC was in progress, and the head temperature rose to $350^{\circ} \mathrm{C}$. Simultaneously, the replenishing reservoir was heated to the same temperature with its internal heater. A piston for the reservoir was then intended to force the liquid lithium through a tube leading to the head at a controlled rate. Instead, the lithium flowed up the tube to the filled head without any motion of the piston. Enough accumulated so as to create a large drop of lithium below the head.

The reservoir heater was turned off and the GDC terminated as soon as this was observed, but not before the drop fell to the bottom of CDX-U. The bulk of the lithium was restricted to a deposit about $13 \mathrm{~cm}$ in diameter and a maximum thickness of approximately $4 \mathrm{~mm}$ (Fig. 7). Lithium spheres with diameters greater than a few millimeters were limited to within about $20 \mathrm{~cm}$ from the center of the main deposit. They were restricted to the disposable stainless steel foil that protected the bottom of the CDX-U vacuum vessel. The area of the lithium was still small compared to the total surface area of the vacuum vessel, and its presence did not affect plasma operations. However, the event did clearly demonstrate the siphoning of liquid lithium up the tube against gravity. 
The argon GDC was used to prepare the L3 for experiments with a clean head kept at above the melting point of lithium (Case C). In Case C (i. e., after argon GDC), deuterium pumping by the limiter became comparable to levels during plasma exposure of the L3 head after it was initially loaded with lithium (Case A). Pumpout rates following a CDX-U discharge are compared in Fig. 8. The rates for a head before plasma exposure (Case A) and shortly after GDC (Case C) are similar, and are higher than with a head after prolonged plasma operation (Case B).

On a typical CDX-U run day, argon GDC was the first activity. The L3 head was then withdrawn from the vacuum chamber. The machine was operated with titanium gettering until reproducible discharges were obtained. There were two titanium getter balls located on the outer wall of the cylindrical CDX-U vacuum vessel, above and below its horizontal midplane. The sublimation rate was kept at the lowest setting of $0.1 \mathrm{gm} /$ hour.

The goal was to achieve plasma currents between 60 and $70 \mathrm{kA}$ for pulse durations of about $15 \mathrm{~ms}$ or more. This was typically accomplished after about ten discharges over approximately an hour. The two gate valves (Fig. 1) were partially closed to prevent the head from being exposed during gettering, while still maintaining vacuum via the main CDX-U pumping system. The L3 head was reinserted into $\mathrm{CDX}-\mathrm{U}$ and plasma operations resumed.

It was possible to change the surface appearance and pumpout rate following this procedure, and experiments were performed with the $\mathrm{L} 3$ head kept above the lithium melting point at $250^{\circ} \mathrm{C}$ with its internal heater (Case C). The results for this case are compared with those for the solid L3 head after plasma operation described earlier (Case B) in Fig. 9. There is a reduction in oxygen and carbon levels, which suggests that a clean lithium surface is effective for gettering. In addition to a lower oxygen emission with the clean L3 head, the discharge is longer because of the reduced radiation losses. 
The low recycling conditions observed during initial plasma operations with the L3 head (Case A), however, were not be recovered. It was also not necessary to have the higher prefill required in Case A to get breakdown. Discharges were then attempted with a head that was subjected to argon GDC as in Case C, but left solid as in the first experiments (Case A). The step of establishing discharges with titanium gettering prior to the reinsertion of the L3 head was also eliminated. These changes also did not recreate the high fueling and low recycling conditions found in Case A.

\section{CONCLUSIONS}

The present work has demonstrated the effects of argon glow discharge cleaning and the safe handling of lithium for ST limiter plasma experiments. Perhaps the most conspicuous result with the L3 was its gettering effect, as shown by the reduction in impurity levels. The observations about particle control are not as clear, since they are consistent with the plasma interacting with high recycling surfaces as well as the L3 head. The main high recycling PFC's in CDX-U were the stainless steel vacuum vessel walls and the boron carbide limiters that were retained on the center stack. Although they were farther away from the plasma than the L3 head, boron carbide limiters were also kept on the top and the bottom of the vacuum vessel to protect these regions.

The initial L3 experiments (Case A) were the first to be performed after a vacuum vessel opening. As is common when the PFC's are poorly conditioned, the discharges had high impurity levels and were short. Since these plasmas did not interact with boron carbide limiters as strongly as they subsequently did, the L3 head may have had a larger relative effect on the recycling for Case A. This presumably diminished as the conditioning of the PFC's improved, and the addition of titanium gettering also reduced impurities.

Once the PFC's are well conditioned, the ratio of low to high recycling surfaces becomes more important. Previous experiments on $\mathrm{T}-11 \mathrm{M}$ with toroidally local limiters, for example, have 
suggested extremely low recycling after extensive conditioning of its lithium limiter.[6] Using their capability to insert carbon and lithium limiters independently, however, the plasma performance was the same when they were compared. Their conclusion is that the dominant effect on the recycling is due to the large surface area coated with lithium following plasma operations, similar to what occurs in probe deposition techniques,[7] rather than the modest area presented by the lithium limiter.

In contrast, there was little evidence for extensive lithium coatings on PFC's inside CDX-U. Fast camera images through a LiI filter $(670.8 \mathrm{~nm})$ suggest that the plasma is interacting with the $\mathrm{L} 3$ head (Fig. 10). Visual inspection of the vacuum vessel after it was vented, however, indicated that the vaporized lithium was restricted to a strip directly above the $\mathrm{L} 3$ head position and about $10 \mathrm{~cm}$ wide. Aside from one limiter in this region, most of the boron carbide limiters that constituted high recycling surfaces in CDX-U remained uncoated.

The lithium experiments to date are complicated by the possibility that surface area is not the only factor that can affect the recycling. On TFTR, for example, the lithium was deposited on well conditioned graphite PFC's.[3] The interaction between the lithium and the carbon created a surface with new chemical properties that may have had a larger effect on the recycling than simply insuring a sufficiently coated area. To help resolve this issue, the next set of experiments are intended to determine the importance of a large lithium surface on the recycling in CDX-U. For this purpose, a fully toroidal lithium limiter has been installed above the floor of the vacuum vessel, as shown schematically in Fig. 1.

The target provided by the new limiter extends radially between its inner and outer sidewalls, which are located at $\mathrm{R}=29 \mathrm{~cm}\left(=\mathrm{R}_{0}-\mathrm{a} / 4\right)$ and $\mathrm{R}=39 \mathrm{~cm}\left(=\mathrm{R}_{0}+\mathrm{a} / 4\right)$. The limiter target will be lithium contained in a stainless steel tray consisting of two 180 degree sectors (Fig. 11). The trays 
have raised edges to hold the lithium, but the surfaces they present to the plasma will be small compared to the overall area of the limiter.

With this geometry, the interaction between the CDX-U plasma and the PFC's should be dominated by the lithium. The limiter target sectors will be mounted on insulators that provide thermal and electrical separation between the limiter target and the vacuum vessel. This will permit GDC in a manner similar to the technique developed for the L3 head.

Acknowledgments

This work was supported by USDOE Contract No. DE-AC02-76-CHO3073.

\section{References}

[1] M. A. Abdou, Y. Ying, N. B. Morley, K. Gulec, S. Smolentzev, M. Z. Youssef, N. Ghoniem, S. Sharafat, T. Sketchley, A. El-Azab et al., APEX Interim Report, UCLA-ENG99-206/UCLA-FNT-107 (1999)

[2] J. Menard, R. Majeski, R. Kaita, M. Ono, T. Munsat, D. Stutman, M. Finkenthal, W. Choe, Y.-S. Hwang, Y. Petrov, G. Gusev, and T. Seki, Phys. Plasmas 6, 2002 (1999)

[3] D. K. Mansfield, K. W. Hill, J. D. Strachan, M. G. Bell, S. D. Scott et al., Phys. Plasmas 3, 1892 (1996)

[4] V. Lazarev et al., 26th EPS Conference on Controlled Fusion and Plasma Physics, Maastricht, The Netherlands, June 14-18 1999, P2.076 (1999)

[5] N. V. Antonov et al., J. Nucl. Mater. 241-243, 1190 (1997)

[6] V. A. Evtikhin, I. E. Lyublinski, A. V. Vertkov, E. A. Azizov, S. V. Mirnov, V. B. Lazarev, and S. M. Sotnikov, 18th IAEA Fusion Energy Conference, Sorrento, Italy, October 4-10 2000, IAEA-CN-77/EXP4/21 (2000)

[7] H. W. Kugel et al., J. Nucl. Mater. 220-222, 636 (1995) 


\section{Figure Captions}

Fig. 1 - Elevation of CDX-U showing the vacuum vessel, field coil configuration, and L3 limiter assembly. The plasma contact points with the L3 limiter head and the fully-toroidal liquid lithium limiter are also indicated.

Fig. 2 - Time evolution of plasma parameters during a typical CDX-U discharge.

Fig. 3 - Photograph of the L3 limiter head prior to plasma explosure. The view is through the side port of the probe drive assembly when the head is in its retracted position. The primary plasma contact position is the region on the bottom and toward the left of the head. The stainless steel mesh surrounding the head can be seen in the section without a lithium coating toward the right of head.

Fig. 4 - Comparison of filterscope data near the start of CDX-U plasma operations with the L3 head and after several discharges. The filterscope viewed the head through a $656.1 \mathrm{~nm} \mathrm{D}_{\alpha}$ filter.

Fig. 5 - RGA measurements during argon GDC. The time dependence of the effluent emission and the temperature of the L3 head are shown.

Fig. 6 - Photograph of the L3 head in the CDX-U vacuum chamber during argon GDC. The center of the head, where the interaction with the plasma was the strongest, still shows a coating. The surface near each end is cleaner. The previously bare region toward the right of the head has become "wetted" with lithium.

Fig. 7 - Photograph of lithium on the bottom of the CDX-U vacuum vessel after it was vented. The bulk of the lithium was localized to a region with thickness of about $3 \mathrm{~mm}$ and a diameter of about $13 \mathrm{~cm}$.

Fig. 8 - RGA measurements of pumpout rates of deuterium following CDX-U discharges. The evolution of the pressure in torr is shown as a function of time in seconds.

Fig. 9 - Filterscope data for the $670.8 \mathrm{~nm}$ LiI and the $441.6 \mathrm{~nm}$ OII emission with (a) liquid lithium L3 head shortly after argon GDC, and (b) solid lithium head after extended plasma operation. The ordinates are in arbitrary units, but reflect the same calibration for each plot. 
Fig. 10 - Photograph of the L3 head during a CDX-U discharge. The underside of the head, which faces the plasma, is viewed through a $670.8 \mathrm{~nm}$ filter. Part of the cylindrical form of the head is outlined by the emission. While the main contact point is near its center, there is also emission near the end of the head.

Fig. 11 - Photograph of the fully-toroidal lithium limiter tray. The cutouts are to accommodate the vertical beam paths for the microwave interferometer and the Thomson scattering laser. 


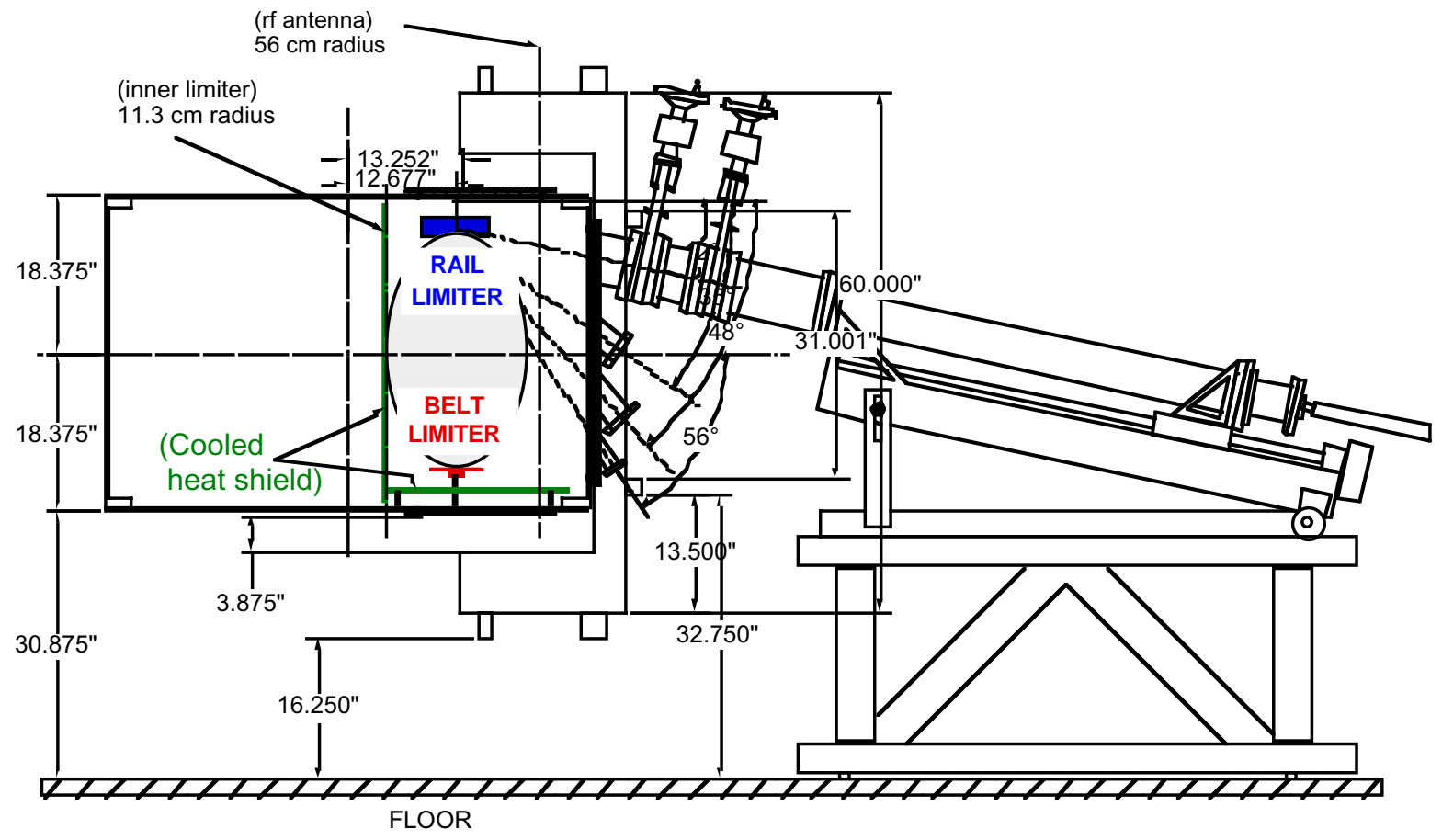

Fig. 1 


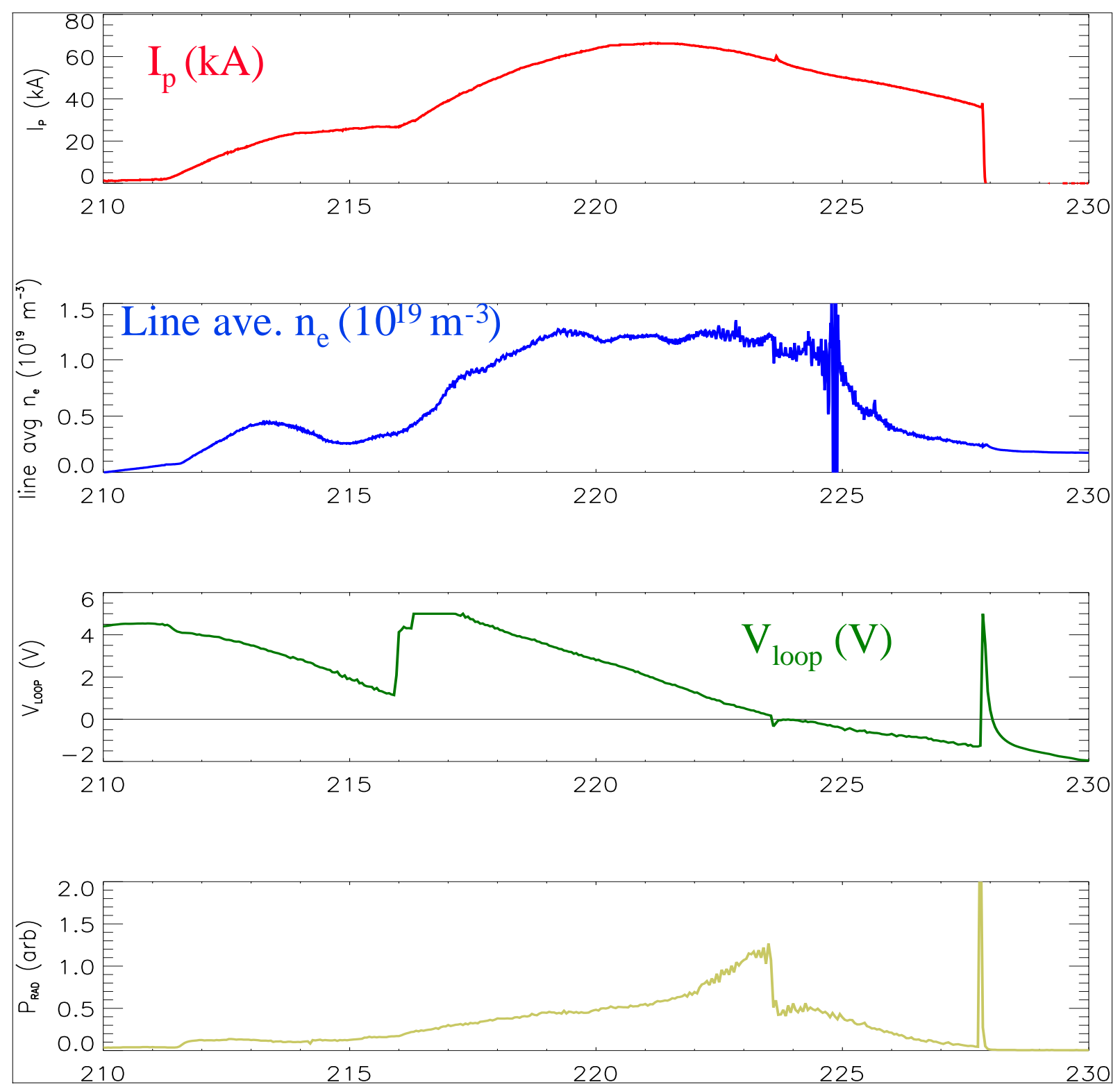

Fig. 2 


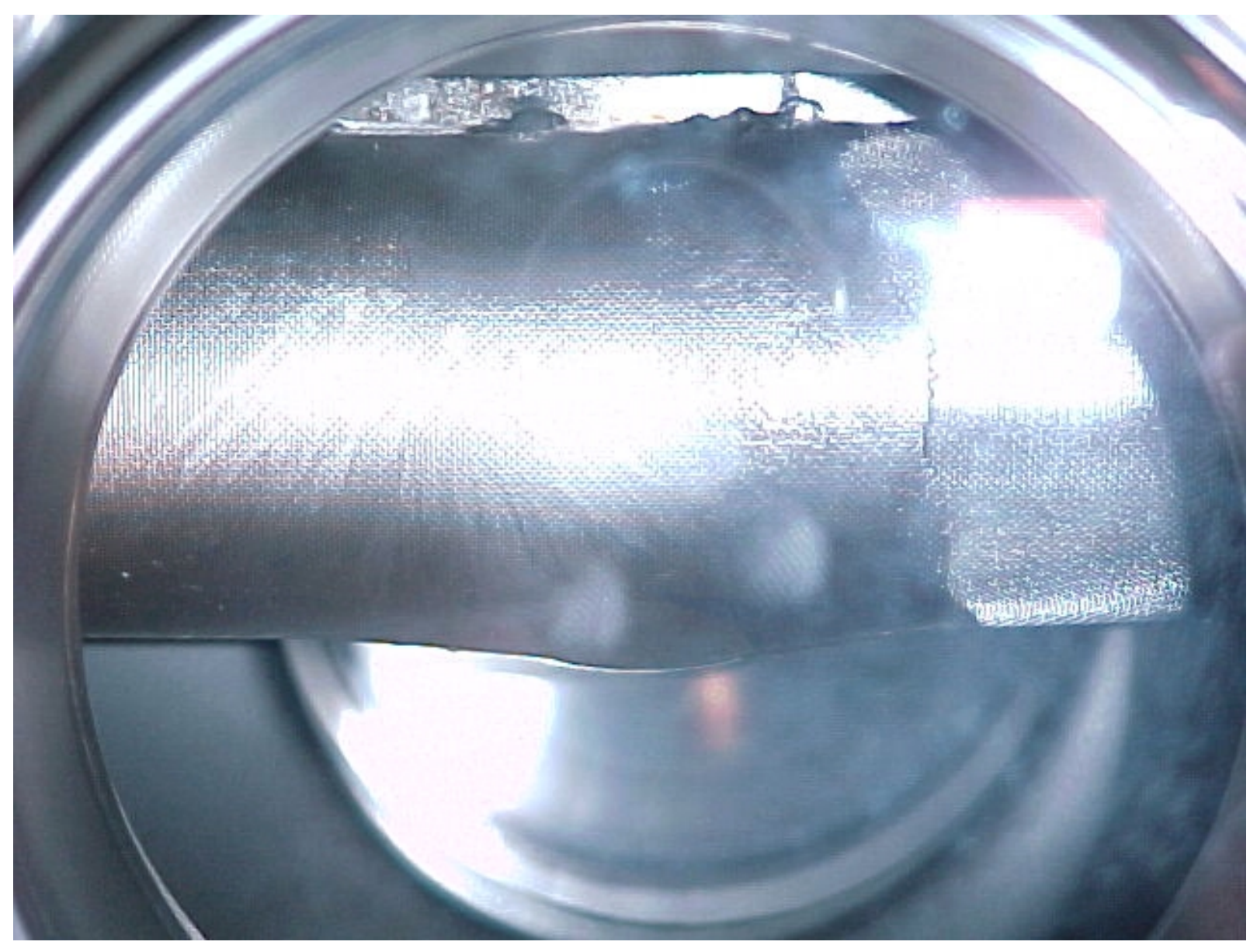

Fig. 3

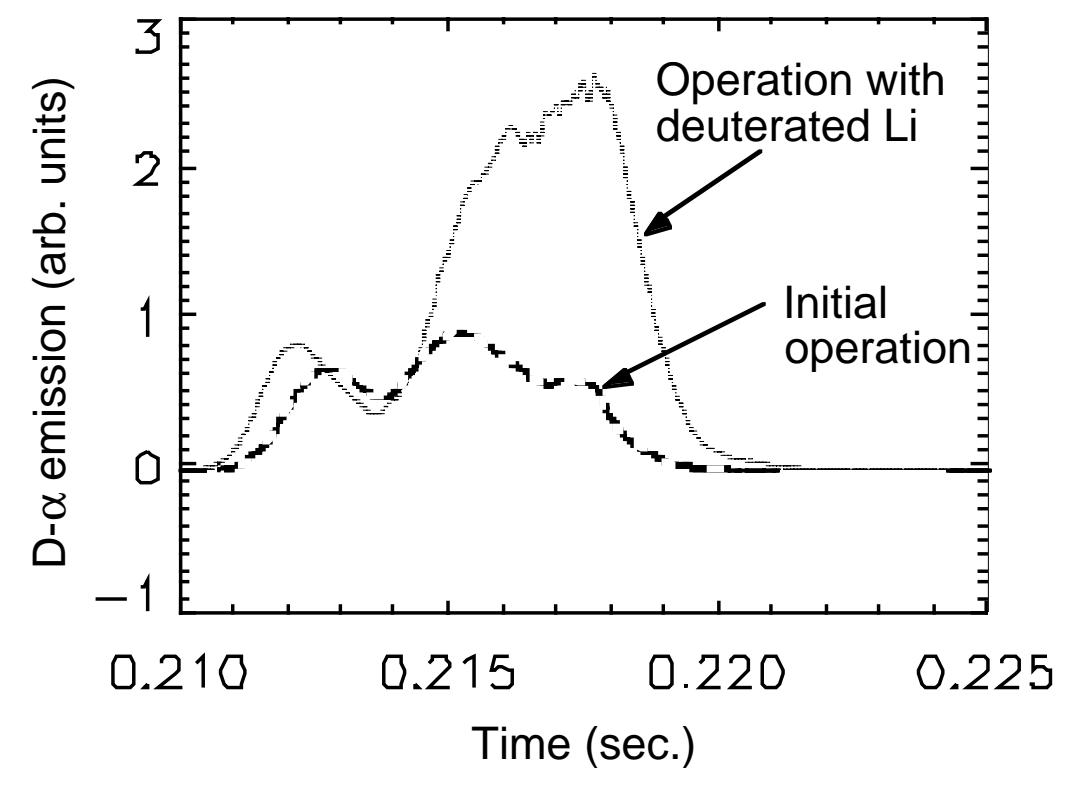

Fig. 4 


\section{PERCENT CHANGE FROM MEAN OF EFFLUENTS DURING Li LIMITER ARGON GLOW CLEANING}

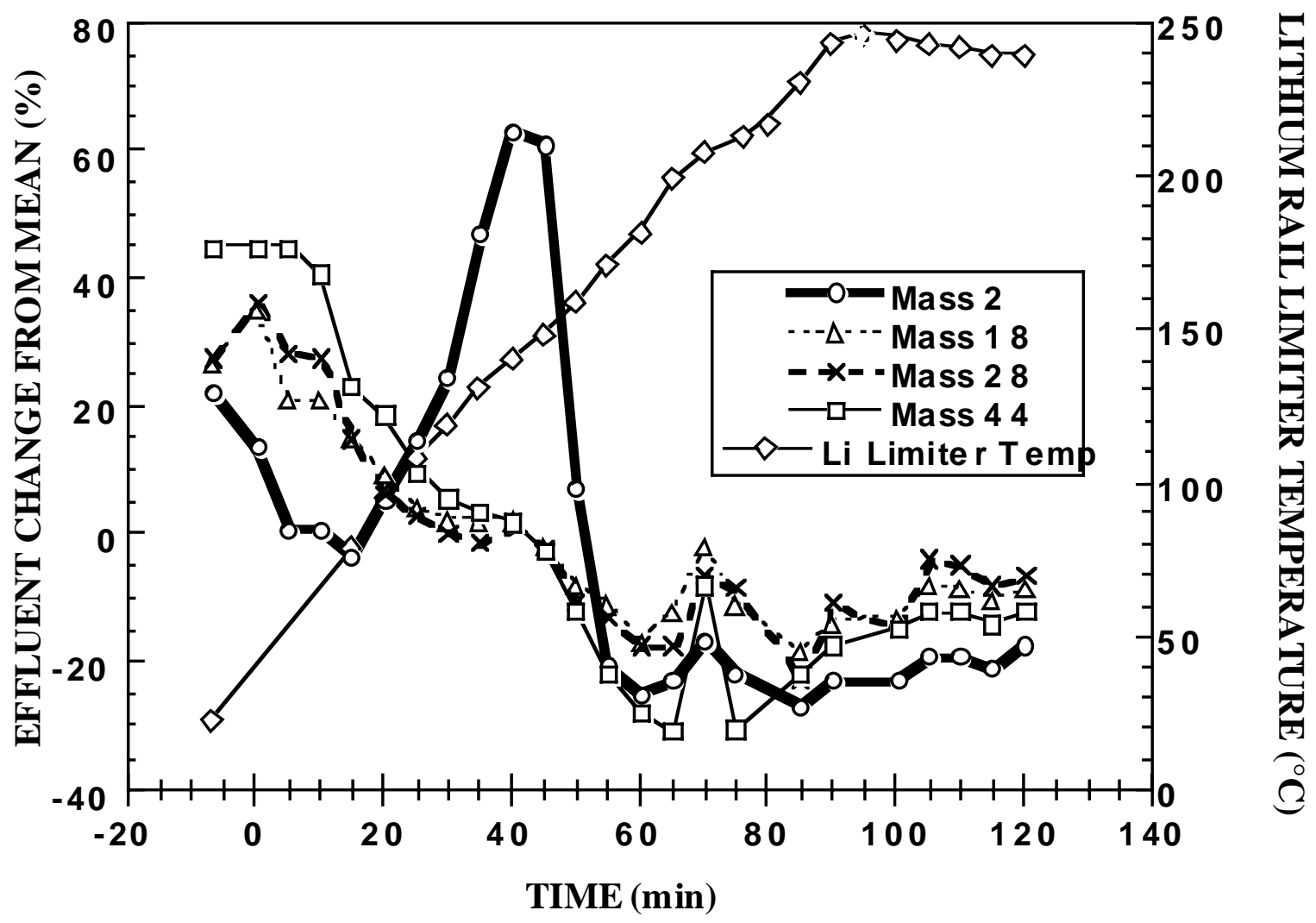

Fig. 5 


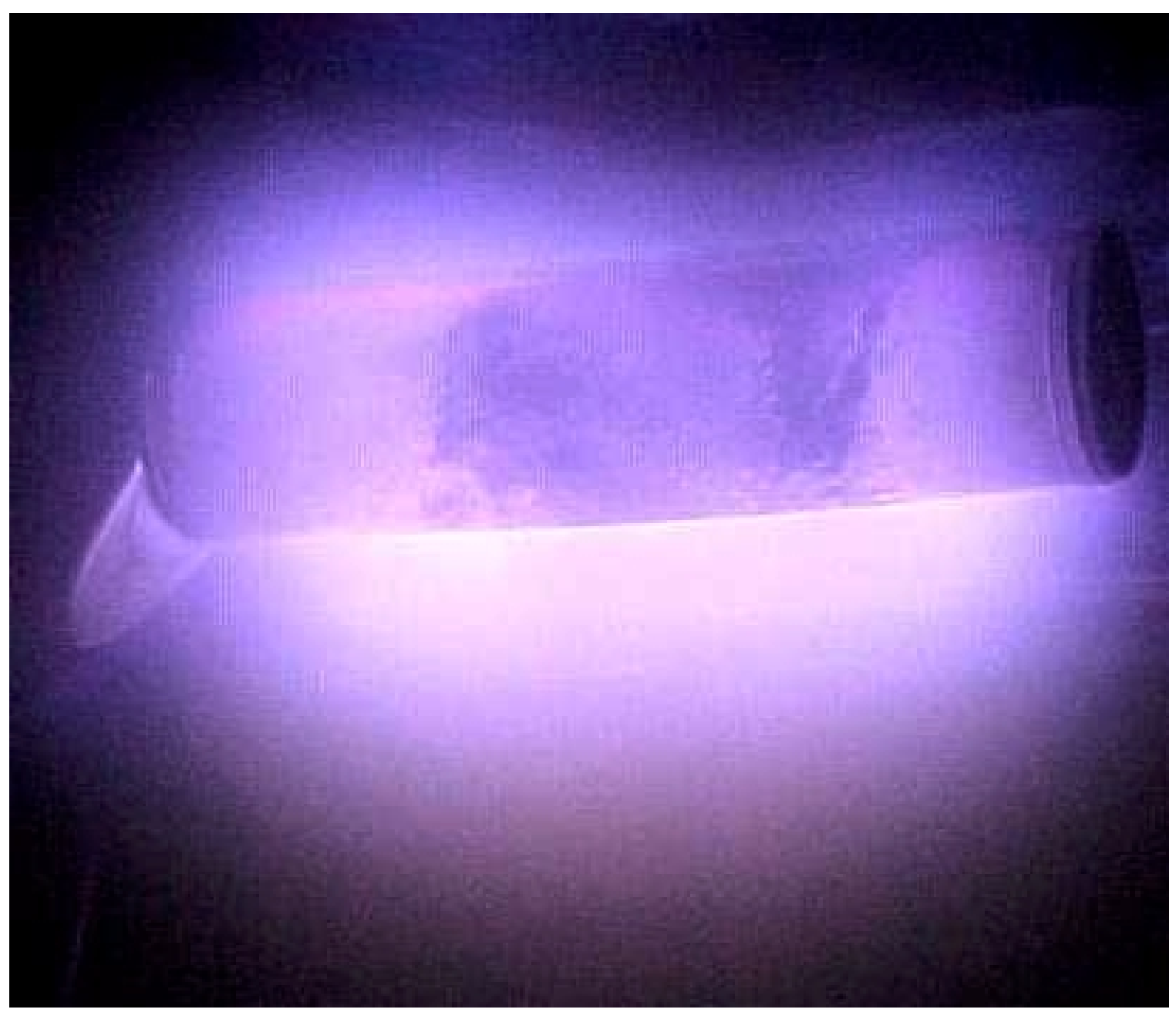

Fig. 6 


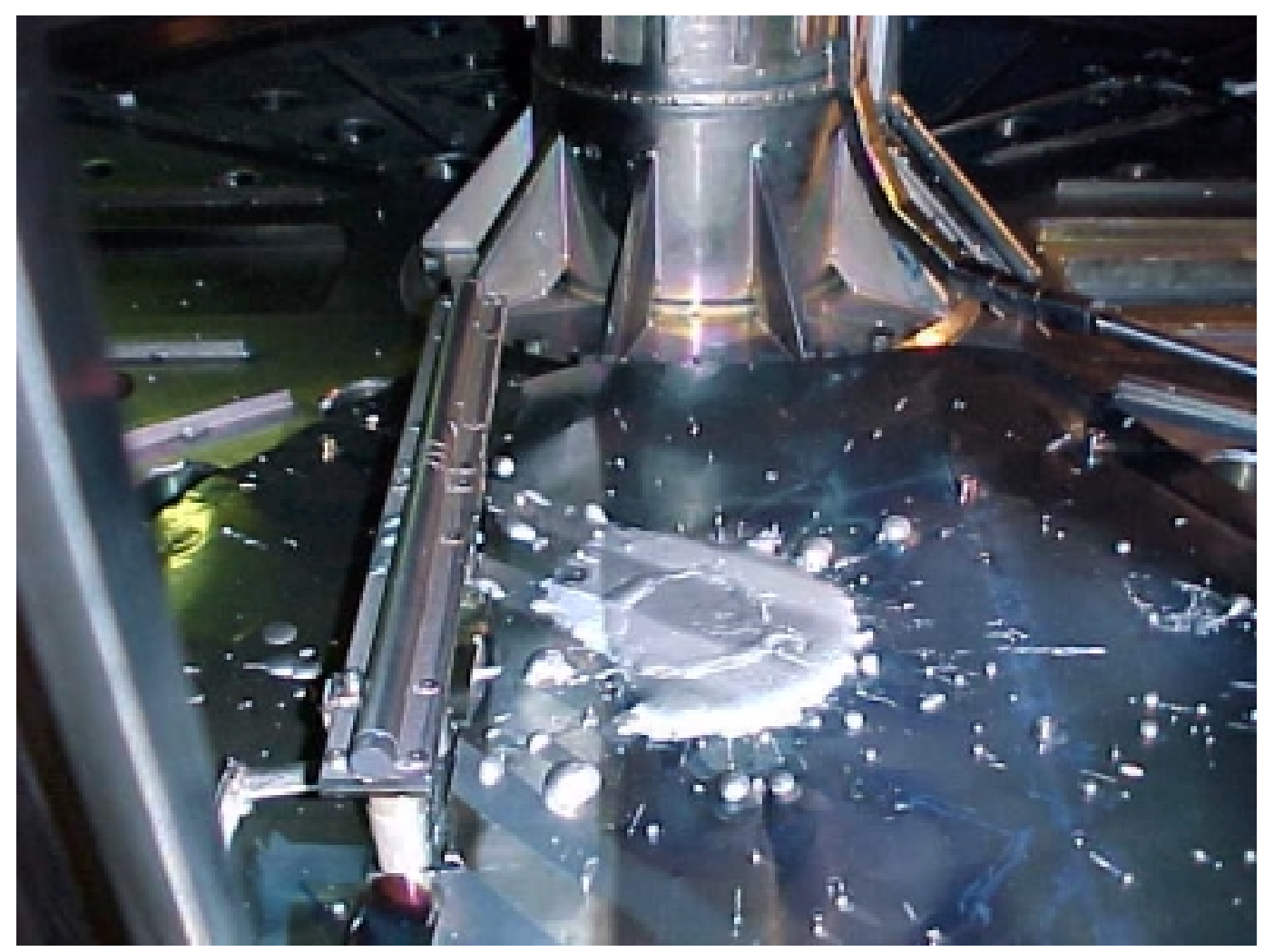

Fig. 7

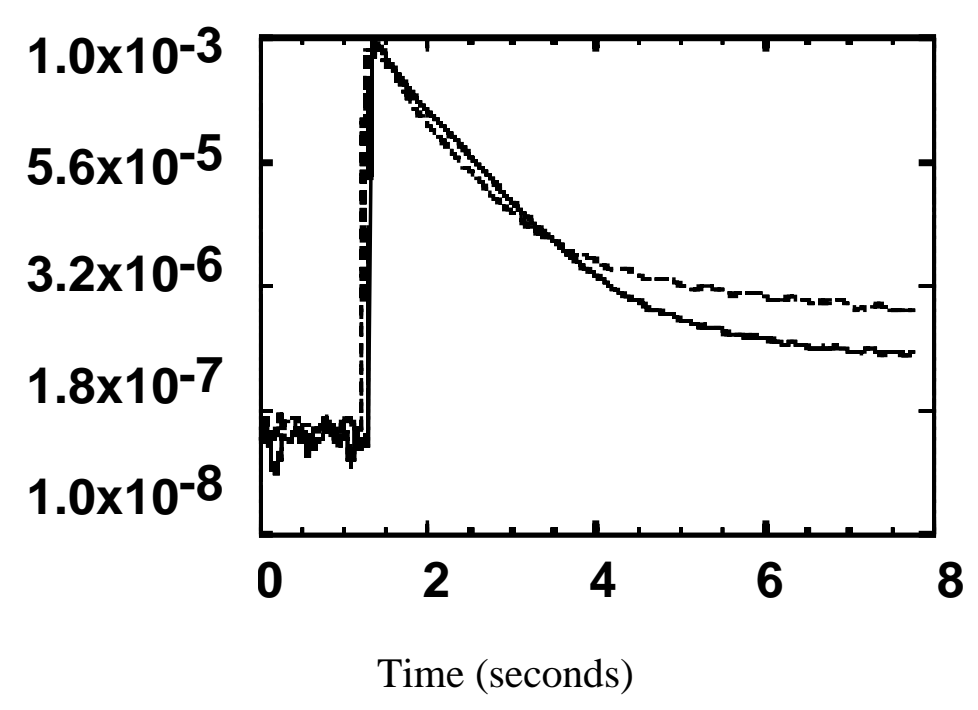

Fig. 8 


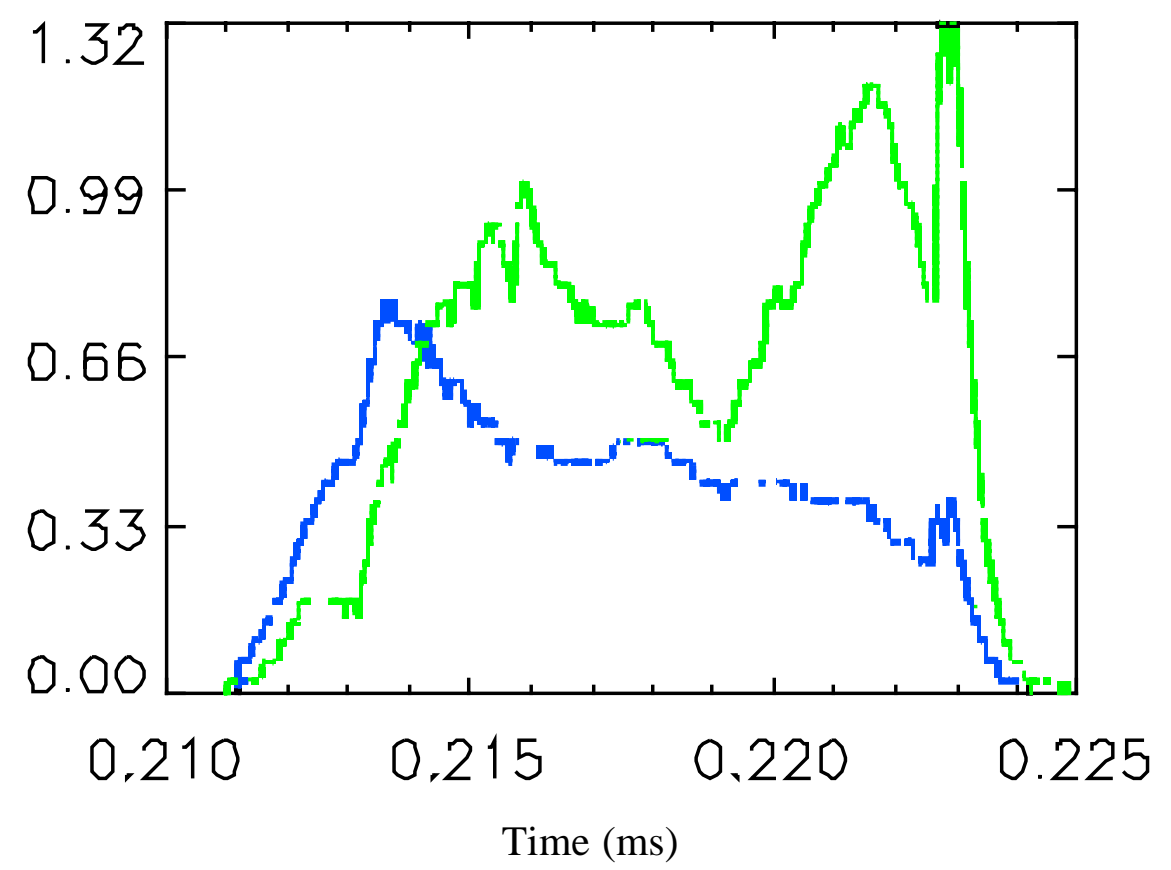

Fig. 9a

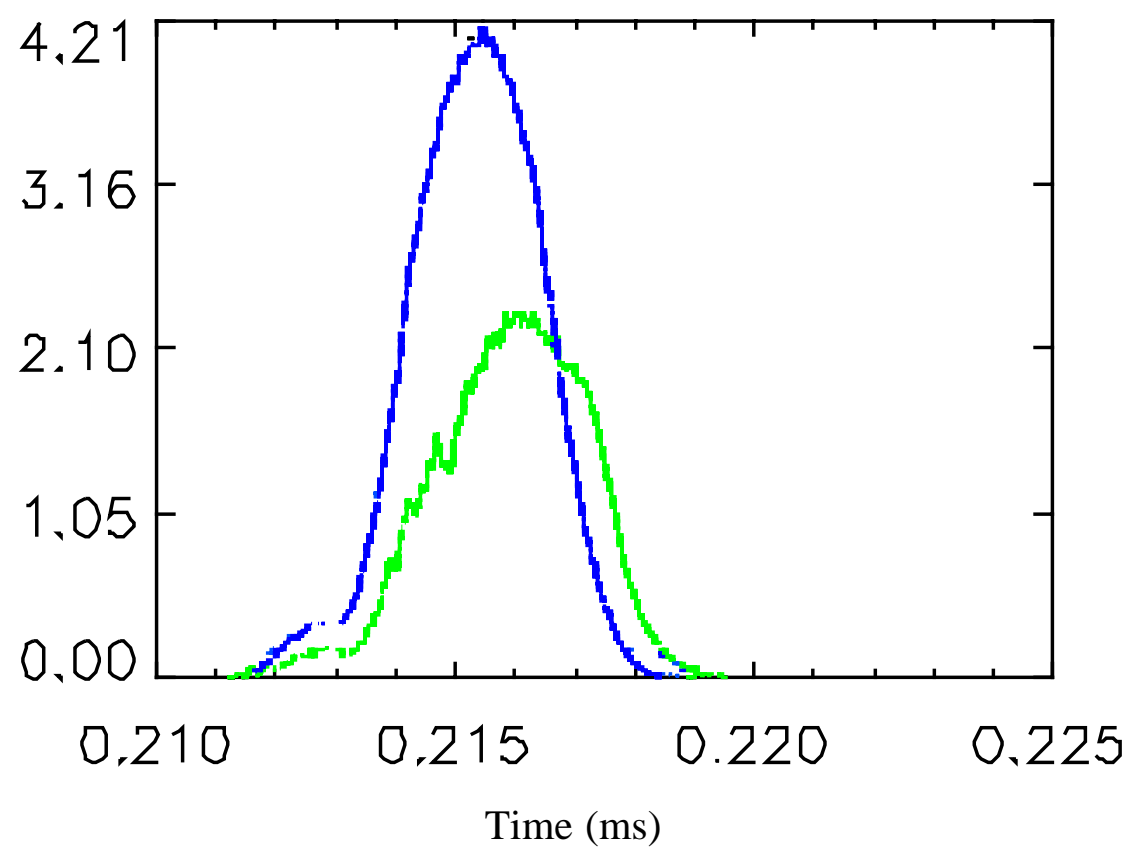

Fig. $9 b$ 


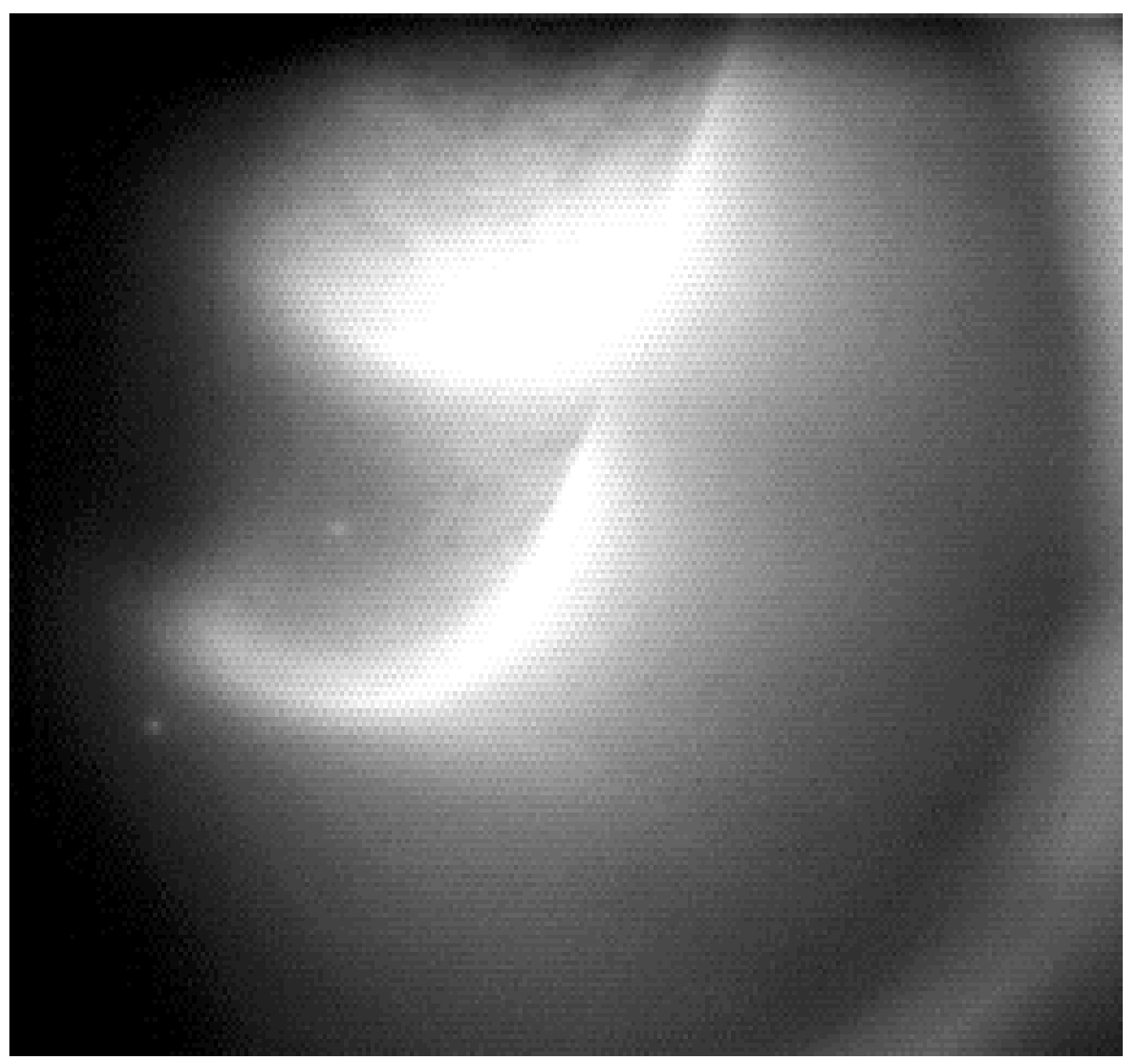

Fig. 10 


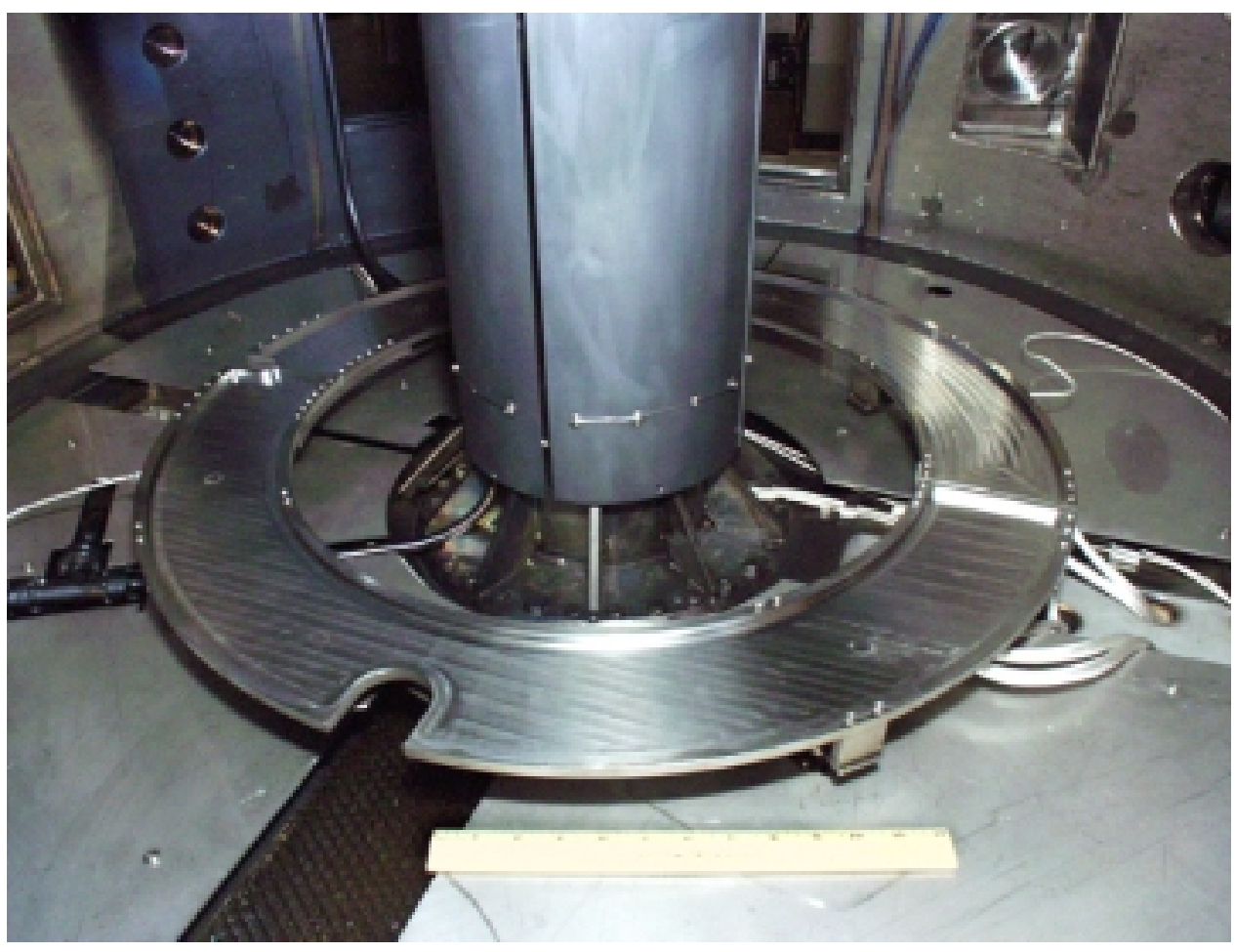

Fig. 11 


\section{External Distribution}

Plasma Research Laboratory, Australian National University, Australia

Professor I.R. J ones, Flinders University, Australia

Professor J oão Canalle, Instituto de Fisica DEQ/IF - UERJ , Brazil

Mr. Gerson O. Ludwig, Instituto Nacional de Pesquisas, Brazil

Dr. P.H. Sakanaka, Instituto Fisica, Brazil

The Librarian, Culham Laboratory, England

Library, R61, Rutherford Appleton Laboratory, England

Mrs. S.A. Hutchinson, JET Library, England

Professor M.N. Bussac, Ecole Polytechnique, France

Librarian, Max-Planck-Institut für Plasmaphysik, Germany

J olan Moldvai, Reports Library, MTA KFKI-ATKI, Hungary

Dr. P. Kaw, Institute for Plasma Research, India

Ms. P.J . Pathak, Librarian, Insitute for Plasma Research, India

Ms. Clelia De Palo, Associazione EURATOM-ENEA, I taly

Dr. G. Grosso, Instituto di Fisica del Plasma, Italy

Librarian, Naka Fusion Research Establishment, J AERI, J apan

Library, Plasma Physics Laboratory, Kyoto University, J apan

Research Information Center, National Institute for Fusion Science, J apan

Dr. O. Mitarai, Kyushu Tokai University, J apan

Library, Academia Sinica, Institute of Plasma Physics, People's Republic of China

Shih-Tung Tsai, Institute of Physics, Chinese Academy of Sciences, People's Republic of China

Dr. S. Mirnov, Triniti, Troitsk, Russian Federation, Russia

Dr. V.S. Strelkov, Kurchatov Institute, Russian Federation, Russia

Professor Peter Lukac, Katedra Fyziky Plazmy MFF UK, Mlynska dolina F-2, Komenskeho Univerzita, SK-842 15 Bratislava, Slovakia

Dr. G.S. Lee, Korea Basic Science Institute, South Korea

Mr. Dennis Bruggink, Fusion Library, University of Wisconsin, USA

Institute for Plasma Research, University of Maryland, USA

Librarian, Fusion Energy Division, Oak Ridge National Laboratory, USA

Librarian, Institute of Fusion Studies, University of Texas, USA

Librarian, Magnetic Fusion Program, Lawrence Livermore National Laboratory, USA

Library, General Atomics, USA

Plasma Physics Group, Fusion Energy Research Program, University of California at San Diego, USA

Plasma Physics Library, Columbia University, USA

Alkesh Punjabi, Center for Fusion Research and Training, Hampton University, USA

Dr. W.M. Stacey, Fusion Research Center, Georgia Institute of Technology, USA

Dr. J ohn Willis, U.S. Department of Energy, Office of Fusion Energy Sciences, USA

Mr. Paul H. Wright, Indianapolis, Indiana, USA 
The Princeton Plasma Physics Laboratory is operated by Princeton University under contract with the U.S. Department of Energy.

\author{
Information Services \\ Princeton Plasma Physics Laboratory \\ P.O. Box 451 \\ Princeton, NJ 08543
}

Phone: 609-243-2750

Fax: 609-243-2751

e-mail: pppl_info@pppl.gov

Internet Address: http://www.pppl.gov 